

\title{
Abstract
}

Poststructuralism, with its critical interpretations of knowledge, discourse, truth, and power, offers a set of compelling analytic tools for disentangling and deconstructing the ways in which health-related phenomena exist and are understood. This paper adopts a poststructuralist stance to outline the impacts of medical hegemony on the lives of people who use drugs, as well as responses to the harms experienced by this population. This analysis reveals how structuralist projects have narrowed the scope and impact of harm reduction through processes of medicalization, neoliberal responsibilitization, and medical co-opting and depoliticization. Nomadic thinking is then introduced as a means for health policy makers and practitioners to transform the boundaries of dominant approaches to harm reduction - particularly, in ways that (re)politicize harm reduction through forms of equity-promoting and social justice-oriented action. Implications for (re)politicized, community-engaged, and structurally responsive approaches to harm reduction in health policy and practice are then discussed.

Key words discourse, harm reduction, medicalization, people who use drugs, poststructuralism

\section{(Re)politicizing harm reduction: Poststructuralist thinking to challenge the medicalization of harms among people who use drugs}

\section{TREVOR GOODYEAR}

\section{Introduction}

The rise of evidence-based practice agendas across Western healthcare and academic settings has distinctly shaped knowledge development and application in healthcare.[1] Within this evolving context, empirically driven ideologies and discourses have manipulated philosophical, disciplinary, and practical orientations to health to be highly medicalized and individualistic.[2,3] For people who use drugs (PWUD), medical hegemony has distinctly contributed to the pathologizing of substance use through the disease model of addiction - a framework for understanding substance use that is limited in scope and that ignores the wider context in which both substance use and substance use-related harms are situated.[4,5] Further still, the advancement of empiricism has had substantial implications for the development and implementation of strategies to support PWUD and promote safer substance use. For instance, although harm reduction has been inclusively conceptualized as "policies, programmes and practices that aim to minimise negative health, social and legal impacts associated with drug use, drug policies and drug laws",[6] it has largely been taken up as a biomedical intervention that is reliant on individual behaviours and the use of technical supports (i.e., healthcare services) to mitigate potential health-related harms (e.g., overdose, infections). The conceptual tension about what constitutes harm reduction and even what is considered to be harms - has led to ongoing philosophical debate concerning the nature and scope of harm reduction.[7] This debate has direct implications for PWUD, as well as for clinical and public health responses to substance use and substance use-related harms. Indeed, while medicalized approaches to harm reduction have been 
greatly effective in mitigating the potential health-related harms associated with substance use,[8-10] this orientation to harm reduction does little to address the broader historical, socio-cultural, and political forces that create and sustain the conditions in which PWUD experience profound health and social inequities.

In Canada and internationally, marginalizing social and structural conditions (e.g., violence, trauma, poverty, lack of quality housing) are well-known determinants of substance use and also create and exacerbate harms among PWUD.[11,12] At the same time, the widespread social stigma and prejudice surrounding substance use have served to further marginalize and "other" populations of PWUD.[13] Processes of social exclusion such as these have also been formalized into practice and worsened by penal drug policies and laws (e.g., the criminalization of substance use, mandatory minimum penalties for drug offences, zero-tolerance substance use policies), which serve to maintain and exacerbate negative societal judgments associated with the presumed moral worth of PWUD.[14-16] Even within healthcare settings, it has been widely recognized that PWUD tend to face stigmatization and violence when interacting with service providers, $[17,18]$ which often prompts PWUD to delay or altogether not access health and social services - including those falling under the umbrella of harm reduction.[19] Across all of these contexts, the health and experiences of PWUD are structurally embedded within systems of domination and oppression (e.g., colonialism, racism, cisheteropatriarchy, classism, poverty) that operate across multiple axes of social location to shape individual experiences (including harms) in continuous and intersecting ways.[11,20] Taken as a whole, the myriad of harms and inequities faced by PWUD represent a near global crisis - one that will require concerted and equity-oriented public health and clinical responses. Within this context, it has aptly been argued that narrowly focused and empirically motivated healthcare orientations to harm reduction have limited potential for meaningfully improving the health and wellbeing of PWUD over the long term.[11]

Given the limitations in highly medicalized approaches to harm reduction, there is need for knowledge about how harmreduction theory and praxis can be advanced to more equitably and more comprehensively support the health of PWUD. To achieve this will require challenging the hegemony of science and grappling with competing notions of knowledge, truth, and action - particularly as they pertain to experiences of human health and illness.[21,22] Thus, in an era of highly medicalized approaches to substance use and harm reduction, this paper seeks to address the following philosophical question: What are the implications of a poststructuralist and nomadic orientation to harm-reduction policy and practice? In doing so, this paper critically analyzes how harm-reduction philosophy and practice have been developed within overarching contexts of medicalization and neoliberalism. The aim of this paper is not to disparage the contributions of empirically driven knowledge in the field of harm reduction, but, rather, to elevate forms of inquiry and action that - although marginalized in practice - have significant potential to critically advance harm reduction in ways that more justly and more comprehensively support the health of PWUD. To do so, this paper first provides an overview of the origins and contributions of poststructuralism as a philosophical perspective in the context of health scholarship. A poststructuralist lens is then applied to the topic of harm reduction and implications for knowledge, discourse, and practice in this substantive area are discussed. Next, this paper highlights the potential of nomadic thinking as a means to challenge and resist the empiricist status quo that has appropriated and medicalized harm reduction. Finally, this paper argues that adopting a poststructuralist and nomadic orientation to harm reduction elucidates the demand for (re) politicizing the state of harm reduction such that health policy makers and practitioners better attend to the marginalizing socio-structural conditions and broader oppressive contexts in which inequities for PWUD are created and reproduced.

\section{Poststructualism: Truth, subversive analyses, and critique}

Poststructuralism is a philosophical perspective that focuses on and interrogates notions of knowledge, discourse, truth, and power, as well as how these notions produce and shape individual identities and subjectivities.[23] In drawing on the works of Mackenzie,[24] Williams,[25] and other prominent poststructuralist figures (e.g., Foucault, Deleuze, Guattari), Holmes and Gagnon[23] argue that the three philosophical assumptions underlying poststructuralism are primarily concerned with truth, subversive analyses, and critique. First, with regard to truth, poststructuralism is concerned with structuralist projects (e.g., empiricism) that attempt to create a rigid and generalizable understanding of the reality or truth of given phenomena.[23] In contrast to the empiricist notion that understandings of phenomena are based on absolute truths, poststructuralism argues that how phenomena are interpreted is a matter of perspective - and that individual perspectives are shaped by structurally imposed societal norms. Poststructuralism draws particular attention to how entrenched systems and structures enact power to shape the types of knowledge that are produced, disseminated, and privileged in society, while simultaneously directing the ways in which these sources of knowledge are codified into societal 
norms and understandings of reality.

Second, poststructuralism calls for subversive analyses about how particular phenomena occur and are understood, thereby prompting consideration of alternative ways of knowing and being that could exist if one were to think differently about a given phenomenon or the world more generally - that is to say, if one were to think beyond structurally imposed understandings of reality.[23] In this way, poststructuralism catalyzes the questioning and reconsideration of structured understandings, rigid assumptions, and dominant perceptions related to what is generally deemed to be good or bad, true or false, expected or unexpected The subversive effects of poststructuralism thereby facilitate the disentanglement and deconstruction of how systems of hegemony shape the ways in which phenomena exist and are understood.[25]

This deconstruction is closely linked with poststructuralism's third principle - critique - which necessitates the critical appraisal of preconceived ways of being and knowing, including, in particular, through "a robust approach and account for the continuous interplay between knowledge and power".[23] In a societal context where multiple structures influence and attempt to govern individual behaviours and attitudes, critique facilitates exposure of the underlying workings through which various forces - be they academic, legal, biomedical, or other - contribute to the subjugation and othering of bodies, knowledge, and practices.[23,26] As argued by Holmes and Gagnon,[23] critique is thus highly politicized and intimately linked with resistance to governmentality and social control, as, according to Foucault, "the art of not being governed or better, the art of not being governed like that and that cost [is the] very first definition of critique".[27] Partnered with subversive analyses, critique serves as a powerful tool for uncovering and pushing back against the inner workings behind empiricist knowledge structures, thereby freeing opportunities for improving social conditions through processes of resistance, resurgence, and counterhegemony.

\section{Poststructualism and harm reduction: knowledge, discourse, and practice}

Poststructuralism facilitates the critical examination of healthrelated knowledge development and application - namely, by exposing how power relations and social realities direct what is observed, considered, and privileged with respect to health and wellbeing.[28] While structuralist projects have shaped health and healthcare in a variety of contexts, the impacts of medicalization on the experiences and realities of PWUD are particularly pronounced. In applying a poststructuralist lens to the specific context of substance use, one begins to see the ways in which harm reduction has been taken up and influenced by medical hegemony. Although the consequences of this coopting are broad in scope, empirically driven structures and processes have largely manipulated harm reduction such that it tends to be operationalized as a form of "population governance" for PWUD.[13] What follows is a poststructuralist analysis of the ways in which medical hegemony has governed and shaped three key facets of harm reduction: knowledge, discourse, and practice.

\section{Biomedical knowledge and the medicalization of harm reduction}

From an epistemological standpoint, structuralist projects have fashioned an empirically driven hierarchization of harm reduction-related knowledge production and application. In exploring the limits and implications of this privileging of medicalized knowledge, poststructuralism draws attention to underlying mechanisms of "how this knowledge is produced and in what context; how scientific claims are made, by whom, and to what end; who the objects and subjects of these forms of knowledge are; and, finally, how these forms of knowledge and the systems that generate them can be destabilized".[23] Within the context of medical hegemony, practices commonly deemed as falling under the umbrella of harm reduction are largely biomedical in nature, and, for instance, include technically oriented interventions and practices, such as opioid agonist therapy, needle and syringe distribution programs, safer drug administration practices, naloxone kit distribution and utilization, sexually transmitted and blood-borne infection treatment and services, and so on.[29,30] These technical approaches to harm reduction are undoubtedly effective in reducing the physiological harms associated with substance use, and they also have had tremendous - even life-saving - impacts on the lives of PWUD.[7] Further, given the clinical challenges posed by the substance use-related health problems many PWUD experience (e.g., complex overdoses, antibiotic-resistant infections, lack of effective pharmacological interventions for methamphetamine dependence), medicalized approaches to harm reduction have a pivotal role to play in advancing substance use care and outcomes for PWUD. Nevertheless, narrowly medicalized approaches to harm reduction emphasize the inherent role, knowledge, and power of service providers in making decisions about and taking ownership of harm reduction.

Indeed, despite PWUD being the end-users of harm-reduction services, medical hegemony has situated biomedically driven knowledge sources and practitioners to be privileged as 
the "experts" - and, in many cases, the gatekeepers - of harm reduction-related information and interventions.[7,31] For instance, despite widespread acknowledgment that the provision of injectable opioid agonist treatment (i.e., prescription hydromorphone or diacetylmorphine) has significant health and social benefits for many people who inject drugs, its availability and accessibility is restricted by an array of clinical and regulatory barriers, including lack of specialist healthcare infrastructure and providers, strict eligibility requirements for treatment initiation (e.g., age, ability to self-administer the medication, DSM-V diagnostic criteria), and approval through regional health-related regulatory bodies (e.g., the Government of Canada's Special Access Programme and List of Drugs for an Urgent Public Health Need).[32] Within the context of this example and other substance userelated intervention landscapes, the service-related barriers experienced by PWUD are further exacerbated by challenging patient-provider power dynamics and widespread experiences of stigma that negatively influence health care access and utilization.[29,33] Through these interrelated processes of medical paternalism and marginalization, healthcare institutions and broader sources of state control effectively dictate which harm-reduction services are available to PWUD, how and when they can be accessed, and to what extent and under which circumstances harm-reduction knowledge and tools are provided. This institutionalized and "one-size-fitsall" healthcare model of harm reduction is grossly inadequate for PWUD,[29] and represents a pervasive source of control and governmentality. To deconstruct and challenge this medicalized model, poststructuralism reveals and critiques how knowledge and information pertaining to harm reduction are both produced and applied to shape and govern the experiences of PWUD.

\section{Medicalized discourses of responsibilitization}

Poststructuralism is concerned with how knowledge interacts with language to shape societal thoughts, assumptions, and practices, thereby facilitating the critique of how dominant discourses enact power to "structure societal life and regulate populations and individuals, while also legitimizing or condemning particular practices".[23] In this way, language and discourse become sites for political resistance against structuralist ideologies that attempt to define individual and social realities.[23,34] For PWUD and health systems and service providers, medical hegemony - despite its assumed intent to promote healthy populations - has profoundly and problematically influenced the discourse surrounding harm reduction to be overly individualistic. Dominant medicalized approaches to harm reduction tend to be laden with neoliberal ideology, which asserts that individuals are freely responsible for their own health and wellbeing, and, further, that suboptimal life conditions or poorer health status are largely due to a lack of effort or agency.[35] For instance, in the context of increasingly fentanyl-adulterated illegal drug supplies and opioid overdose crises internationally, emerging public health responses have called for PWUD to reduce overdose risk by agentively taking up drug-checking technologies to screen their substances for the presence of fentanyl and other synthetic analogues (i.e., highly potent opioids).[36] Responses such as these reflect neoliberal discourses of "responsibilitization",[29,37,38] which have largely positioned the burden of mitigating substance userelated harms with PWUD themselves, thereby diffusing and redirecting state responsibility for taking action to promote safer substance use, such as by providing a safe and regulated drug supply. The products of this discourse constitute a highly decontextualized and narrow conceptualization of harm reduction, which emphasizes the role of resiliency-based processes of self-care and self-management for PWUD to mitigate harms, and which does not take into account the many socio-structural barriers (e.g., stigma, criminalization) that restrict opportunities for PWUD to use substances more safely and to access harm-reduction services.[7,39,40]

The discourse surrounding harm reduction is closely intertwined with medicalized notions of surveillance - notions that are formally structured into reality via epidemiological tools and methods. As argued by Jiao,[7] the medicalization of harm reduction has been primarily driven by knowledge stemming from epidemiology,[39] which is a field that privileges scientific claims related to concepts of disease, risk factors, and at-risk subjects,[41] and that is concerned with generalizable, combinable, and comparable constructions of risk[42]. The epidemiological focus of harm reduction is evident in the widespread and structured monitoring of substance use-related adverse outcomes (e.g., druginduced psychosis, incarceration [due to the criminalization of substance use], overdose, and the transmission of bloodborne infections,). While knowledge obtained through these risk-focused epidemiological means certainly has a role to play in informing harm-reduction policy efforts and priorities, data of this sort often lack sufficient attention to the impacts of broader socio-contextual influences on the health of PWUD,[7] such as laws and policies, social and structural determinants of health, and intersecting systems of power and oppression. Given this lack of accounting for contextual influences on substance use and health, epidemiology has been criticized as "serv[ing] as an extension of surveillance medicine through the vehicle of governmentality",[43] as surveillance and the wider medicalization of harm reduction unjustly exert "bio-power" [44] 
to structure societal life and regulate and govern the lived realities of PWUD.[13,45] Indeed, the rhetoric surrounding medicalized harm reduction largely has privileged the concept of "risk management" for PWUD - thereby operationalizing surveillance discourse through notions of governance and control over populations, their behaviours and practices, and the corresponding risks that populations both create and to which they are subjected.[43,46] This epidemiologically driven labelling of individuals and populations as "risky" exacerbates the marginalization of PWUD and invokes processes of internalised self-surveillance,[47] as "this labelling encourages self-regulatory neo-liberal strategies that capitulate to state power".[13] Poststructuralism draws attention to the ways in which societal norms, expectations, and practices related to substance use and harm reduction stem from and reinforce a variety of social institutions - including medical hegemony and neoliberalism. Structuralist projects such as these exert power in ways that influence the construction of understandings of health, risk, responsibility, the self, and; $[23,34]$ in the context of substance use, dominant discourses embedded within these institutions have distinctly shaped harm reduction in ways that are individualistic, context-stripped, and often detrimental to the health and wellbeing of PWUD.

\section{Medical hegemony and the depoliticization of harm reduction}

Along with its vast influences on knowledge and discourse, medical hegemony also has depoliticized harm-reduction policy and practice. Here, poststructuralism draws attention to the ways in which structuralist projects influence and govern harm reduction, and, as a counteraction, identifies opportunities for political processes of critique and resistance.[23] Historically, harm reduction originated from informal - and, at the time, "radical" - grassroots practices led by PWUD and allies, including the then-illegal distribution of sterile injection equipment.[48,49] Despite its politicized and community-based origins, however, harm reduction largely grew in prominence and was formally codified into healthcare practice after it was taken up by epidemiological and public health stakeholders - specifically, to reduce HIV transmission during the height of the crisis.[29] This scale-up and institutionalization of harm reduction across medicalized structures and contexts was greatly advantageous for communities of PWUD, as it facilitated efforts to bolster the harm-reduction movement and further promote health care and outcomes PWUD;[29] however, it has also "washed out" and marginalized the grassroots experiences and efforts of people with lived experience of substance use. This co-opting has sanitized the oppositional political origins of harm reduction as a "platform for broader and more structural social change".[50] In commandeering the harmreduction movement toward one focused on risk reduction and individual strategies and interventions for mitigating substance use-related harms, medical hegemony has both disrupted community agency and solidarity in taking up harm reduction as a fundamentally "anarchist-inspired form for practice".[48] In doing so, control and authority over harmreduction services largely have been removed from the communities who access, experience, and are most impacted by them.[29] Here, poststructuralism resists totalizing processes of medicalization and depoliticization to identify avenues for (re)politicizing the future of harm reduction in ways that more critically and equitably support the health and wellbeing of PWUD.

\section{Nomadic harm reduction: Alternative and more comprehensive paths forward}

Poststructuralist approaches to health-related scholarship and practice support resistance to and deterritorialization from empirically driven, rigid, and medicalized orientations to human health.[23] From a poststructuralist standpoint, nomadic thinking offers a distinctly political method for understanding the ways in which certain types of knowledge and priorities are devalued within overarching healthcare contexts, and, in doing so, of disrupting dominant ways of thinking and doing health policy and practice.[51] In effect, nomadic thinking refers to freeing oneself from codification and stratification (i.e., thinking beyond structurally imposed understandings and realities), while also theorizing opportunities for resistance and subversive action.[23] Although there is no one proclaimed, structured, formulaic way of engaging in nomadic thinking - due, in part, because of its evolution and growth according to diverse environments, contexts, and relationships - engaging in this sort of thinking privileges notions of openness, creativity, and subversion that are required to reorient and transform dominant approaches to knowledge and practice.[52] Given the extent to which empirically driven ideologies direct health policy and practice agendas,[1-3] including those related to substance use and harm reduction, $[4,6]$ and given that overly medicalized approaches are inadequate for addressing the structurally embedded harms facing PWUD, the need for concerted political thought and action in pertinent healthcare contexts is paramount. Here, nomadic thinking facilitates the expansion of medicalized approaches to harm reduction and, in doing so, (re)directs healthcare system and stakeholder attention toward the highly political foundations underpinning the harmreduction movement. For health researchers, policy makers, 
and practitioners, embracing this nomadic school has critical implications related to the ways in which harm reduction is conceptualized and mobilized into action. As outlined in detail below, nomadic thinking in healthcare contexts can serve to better center harm reduction toward the experiences of its service users, broaden the focus and aims of harm reduction to include socio-structural considerations, and reorient harm reduction to be taken up as a platform for social change.

\section{Centering the experiences of PWUD}

Nomadic thinking offers a grassroot means for revolutionizing the boundaries of prevailing orientations to harm reduction. Nomad science is unmistakably political in that it is subversive in intent and, further, is aptly responsive and oriented toward the emerging needs of its service users[28,53] - in this case, PWUD and allies at the forefront of harm-reduction practice. For health policy decision-makers, the recognition of service users as nomadic and transformational subjects is urgently needed to disrupt the narrow reliance on medicalized approaches to harm reduction. Indeed, despite facing historic and ongoing political scapegoating, stigmatization, and repression by marginalizing socio-structural forces,[13] PWUD remain steadfast in their ability to organize and champion change in order to protect themselves and their communities from harms.[48] For example, in response to the opioid overdose crisis and limited access to spaces in which substances can be used safely (e.g., wherein overdose events can be appropriately responded to), communities of PWUD across Canada have rallied together to implement muchneeded overdose prevention sites. Largely operating outside of governmental approval processes and requirements (e.g., related to: staffing, operational models), overdose prevention sites are often peer-led and designed to offer low-threshold and accessible services. While a testament to the community strength and resiliency of PWUD, overdose prevention sites also reveal critical limitations to the state-sanctioned response to the overdose crisis, including the lack of infrastructure for healthcare system-implemented safer consumption sites, as well as inadequate public backing for (or, some contexts, stark opposition to) community-driven overdose crisis response efforts.[13,31] Here and in other intervention contexts, the harm-reduction efforts of PWUD regularly operate independently of or without significant support from health policy actors and associated resources (e.g., funding) - due, in large part, to continued, negative societal judgments and dominant norms (e.g., punitive control, stigma, social exclusion) toward PWUD.[13,54] Within this context, nomadic thinking challenges the ways in which dominant discourses continue to marginalize and sideline the experiences of
PWUD, while simultaneously thwarting the development and expansion of community-informed harm-reduction efforts.

For healthcare providers and institutions, the subversive intentions underpinning nomadic thinking serve to disrupt the status quo of medicalized approaches to harm reduction, thereby freeing opportunities for (re)centering harm reduction toward the diverse needs and experiences of its service users. Consider, for example, that hospitals in many settings, including in Canada, have paternalistic and abstinenceoriented drug policies that expect PWUD to use only a prescribed dose of a substance, to alter the route of substance administration, or to abstain from substance use while in hospital.[17,18,55] Such policies restrict opportunities for safer substance use (e.g., by denying access to certain harmreduction services, such as sterile injection supplies and safer consumption sites within hospital settings), and also structure hospitals as risk-environments in which PWUD experience a series of adverse outcomes, including experiences of leaving hospitals "against medical advice," high hospital re-admission rates, and increases in morbidity and mortality - often due to nontreatment or undertreatment of the health conditions for which they were originally hospitalized.[56] Within the context of this example and others, nomadic thinking privileges marginal experiences and perspectives and, in doing so, draws attention to opportunities to more equitably support PWUD. This may include, for example, hospital policies that are grounded in harm reduction, as well as clinician approaches that are, relational, nonjudgmental, responsive to power imbalances, and respectful of the agency and subjective and situational needs and experiences of PWUD. Nomadic thinking in healthcare therefore expands conceptualizations of harm reduction in ways that more fulsomely attend to the practices, supports, and needs which PWUD themselves are bested suited to determine are the most helpful and most urgently warranted.[29] In doing so, nomadic thinking provides the foundation for collaborative action as a means for grassroots harm-reduction work across pertinent health policy and systems-level contexts.

\section{Broadening the scope of harm reduction}

In applying a nomadic and poststructuralist lens to harm reduction, clinicians working alongside PWUD can facilitate opportunities for broadening the scope of harm reduction beyond medicalized knowledge and physiological harms. While institutionalized and depoliticized approaches to harm reduction largely have taken after biomedical models that locate health at the static and context-stripped intersection of substance use and the individual,[48] nomadic thinking privileges knowledge and action that exist outside of medical 
hegemony and that tend to be pushed to the margins.[28,57] For example, within a healthcare context where PWUD are often positioned as passive recipients of care who are acted upon in their "best interests" by "expert professionals," such as clinicians and policy makers,[58] nomadic thinking - with its careful deliberation about subjectivity and multiplicity in points of view - departs from "top-down" and medicalized ways of thinking by broadening the scope of factors considered in harm-reduction practice. In effect, nomadic approaches to harm reduction in clinical contexts more fully consider the interplay of alternative sources of knowing, such as experiential and contextual knowledge (e.g., stemming from constructivist and critical theory paradigms, respectively). $[7,13]$ This broader and more pluralistic epistemological stance supports greater heterogeneity and nuance in clinician approaches to harm reduction, which is of critical importance in addressing the socially and structurally embedded harms faced by PWUD. For instance, in accounting for non-medicalized sources of knowledge within healthcare encounters, space is created for expanded conceptualizations of harm reduction that consider both physiological and social harms (e.g., stigma, criminalization, poverty). Knowledge gained through these means draws attention to how susceptibility to harms (both physiological and other), as well as the capacity for PWUD to take up harm-reduction strategies and attend to their own health and wellbeing, are situated within broader social, economic, political, and structural contexts.[7] This expanded approach to harm reduction prompts greater clinician awareness of the common problems and barriers to safer substance use faced by PWUD, and thus creates opportunities for tailoring harm reduction efforts to more effectively support PWUD. Indeed, through deeper consideration of diverse sources and types of knowledge, nomadic thinking begins to distil some of the ways in which harm-reduction policy and practice can metamorphosize to be more comprehensive and responsive to social contexts of PWUD's lives.

\section{Harm reduction as a platform for social change}

In broadening the scope of harm reduction, opportunities for further articulating its underlying intentions and goals are also revealed. Poststructuralist critique serves as a tool for examining the extent to which harm-reduction efforts have been subdued by ideological systems of beliefs - namely, prevailing discourses of medicalization and neoliberalism. Relatedly, nomadic thinking, with its acknowledgment and promotion of multiple discourses, offers a unique avenue for expanding and politicizing harm-reduction policy. Specifically, nomadic thinking supports the dismantling of individualistic, egalitarian, and context-stripped neoliberal discourses - discourses that stand in opposition to the democratic decisionmaking and collective grassroots action bases upon which harm reduction was originally founded.[7] With its inherent resistance to "being confined within political and ideological systems of totality",[53] nomadic thinking resists conforming exclusively to existing medicalized and depoliticized discourses and, instead, privileges alternative and marginal discourses. This commissioning of marginal (i.e., nomadic) discourses, such as social justice discourses, is needed for healthrelated policy makers to reorient philosophical and pragmatic orientations to harm reduction toward the structural drivers of inequities facing PWUD.[7,12] In adopting a social democratic orientation to harm reduction, the assumed responsibility in preventing and addressing harms faced by PWID is shifted specifically, from lying with the individual to more justly being a moral obligation of society and the state. Given the contested history and ongoing nature of the state-sanctioned war on drugs, those who use them, and those who sell them,[48] however, specificity with regard to what should constitute this societal response is warranted.

Critically oriented and equity-promoting harm reduction.

From a systems-level and structural standpoint, nomadic thinking in the context of harm-reduction policy prompts a critical reconsideration of the causes of harms for PWUD. Extending upon the political nature of nomad science and social democratic beliefs that it is a social responsibility to address harms faced by PWUD, a nomadic reading of harm reduction accounts for the ways in which socio-political influences both create harms and constrain opportunities for reducing harms. In close alignment with the anarchistic and action-oriented roots upon which harm reduction was founded.[48] nomadic thinking offers a critical method for disrupting the rigid, individualistic, and narrowly structured orientations to harm reduction that tend to be imposed by medical hegemony.[53] With its subversive intent, nomad science precipitates an expansion beyond the medicalized view that PWUD themselves create harms (e.g., due to lack of agency, effort, and/or willingness), and instead directs attention to the ways in which socio-structural conditions cause and exacerbate harms for PWUD. This a prudent and urgently needed shift in health practice and philosophy, as the status quo of medicalized and depoliticized approaches to harm reduction are insufficient for addressing the structural drivers of inequities faced by PWUD.[12] Within pertinent health and social policy arenas, nomadic thinking - beyond its many other advantages - is perhaps most conducive to (re) politicizing harm reduction such that it places social factors, human rights, and equity more firmly in the foreground of 
approaches to supporting PWUD. Through this lens, harmreduction approaches and interventions become more strongly integrated within a broader social justice framework - explicitly, one that adopts a primary health care orientation and that seeks to improve the social determinants of health for PWUD.[12]

Harm reduction, reconceptualized through perspectives of poststructuralism and nomadic thinking, is thus presented as a more structurally responsive approach than the existing and limited-in-scope medicalized state of affairs. While harm reduction is not a panacea in that it alone is expected to address all of the social oppressions experienced by PWUD,[11] it does provide a critical lens for illuminating and addressing the harmful social conditions in which the lives and experiences of PWUD are situated. In this way, opportunities are revealed for expanding the scope and impact of harm reduction, including, in particular, by strengthening the demand for social justiceoriented and equity-promoting political action. As argued elsewhere,[11-13,59] there is a critical need for clinicians and policy makers engaged in harm-reduction efforts to be attuned to and responsive toward the intersecting systems of power and oppression that impose structural violence and harm against PWUD. Here, a nomadic and (re)politicized orientation to harm reduction demands a critical examination of all levels of social determinants and policies (e.g., penal, housing, welfare, health) that influence opportunities for health and wellbeing for PWUD.[11,12] In this way, the primary focus of harm reduction becomes neither substance use nor individual; instead, this (re)politicized reading of harm reduction is more critically oriented toward the myriad of other contextual influences that give rise to and sustain inequities facing PWUD.

\section{Conclusion}

Although empirically driven and medicalized approaches to harm reduction have led to pronounced reductions in the occurrence of physiological harms among PWUD, these approaches also have inadvertently narrowed the scope of harm reduction through processes of medicalization, neoliberal responsibilitization, and depoliticization. As a counterbalance to this hegemony, poststructuralism provides a critical analytic framework for exposing and critiquing the many unanticipated consequences of medicalization on the lives of PWUD. Moreover, nomadic thinking offers a means for disrupting and transforming the boundaries of dominant approaches to harm reduction. Specifically, nomadic thinking in healthcare contexts can strengthen opportunities to center harm reduction toward the experiences of its service users, broaden its focus and aims to include socio-structural considerations, and catalyze opportunities for equity-oriented social change. Conceptualized in these ways, tactics for health policy and practice stakeholders to (re)politicize the state of harm reduction are illuminated. Now, the challenge will be to take up these calls and diverge from the status quo of harm reduction. Given inequities faced and given that concerted political action and long-term structural changes are required to promote the health of PWUD in equitable and meaningful ways, the need to (re)politicize harm reduction in healthcare is paramount.

\section{References}

1.Thorne S, Sawatzky R. Particularizing the general: Sustaining theoretical integrity in the context of an evidence-based practice agenda. Adv Nurs Sci. 2014;37(1):5-18.

2.Holmes D, Perron A, O'Byrne P. Evidence, virulence, and the disappearance of nursing knowledge: A critique of the evidence-based dogma. Worldviews Evidence-Based Nurs. 2006;3(3):95-102.

3.Rycroft-malone J, Titchen A, Kitson A, Mccormack B. What counts as evidence in evidnece-based practice? Nurs Healthc Manag Policy. 2004;47(1):81-90.

4.Lewis M. Addiction and the brain: Development, not disease. Neuroethics. 2017;10(1):7-18.

5.Frank LE, Nagel SK. Addiction and moralization: The role of the underlying model of addiction. Neuroethics. 2017;10(1):129-39.

6.Harm Reduction International. What is harm reduction? [Internet]. 2019 [cited 2019 Oct 22]. Available from: https:// www.hri.global/what-is-harm-reduction

7.Jiao S. Harm reduction: Philosophical drivers of conceptual tensions and ways forward. Nurs Inq. 2019;26(2):1-6.

8.Drucker E, Anderson K, Haemmig R, Heimer R, Small $D$, Walley $A$, et al. Treating addictions: Harm reduction in clinical care and prevention. J Bioeth Inq [Internet]. 2016 Jun;13(2):239-49. Available from: https://doi.org/10.1007/ s11673-016-9720-6

9.Marlatt G., Larimer M., Witkiewitz K. Harm reduction: Pragmatic strategies for managing high-risk behaviors. New York, NY: Guilford Press; 2012.

10.Pates R. Harm reduction in substance use and high-risk behaviour: International policy and practice. Chichester, West Sussex, UK: Wiley-Blackwell/Addiction Press; 2012. 
11.Smye V, Browne AJ, Varcoe C, Josewski V. Harm reduction, methadone maintenance treatment and the root causes of health and social inequities: An intersectional lens in the Canadian context. Harm Reduct J. 2011;8:1-12.

12.Pauly B. Harm reduction through a social justice lens. Int J Drug Policy. 2008;19(1):4-10.

13.Souleymanov R, Allman D. Articulating connections between the harm-reduction paradigm and the marginalisation of people who use illicit drugs. Br J Soc Work. 2016;46(5):142945.

14.van der Meulen E, Shalit A De, Ka Hon Chu S. A legacy of harm: Punitive drug policies and women's carceral experiences in Canada. Women Crim Justice [Internet]. 2018;28(2):8199. Available from: https://doi.org/10.1080/08974454.201 7.1307160

15.Cavadino M, Dignan J. Penal policy and political economy. Criminol Crim Justice. 2006;6(4):435-56.

16. Marshall SG. Canadian drug policy and the reproduction of Indigenous inequities. Int Indig Policy J. 2015;6(1):1-19.

17.Grewal HK, Ti L, Hayashi K, Dobrer S, Wood E, Kerr T. Illicit drug use in acute care settings. Drug Alcohol Rev. 2015;34(5):499-502.

18.Ti L, Voon P, Dobrer S, Montaner J, Wood E, Kerr T. Denial of pain medication by health care providers predicts in-hospital illicit drug use among individuals who use illicit drugs. Pain Res Manag. 2015;20(2):84-8.

19.Pauly B, MacKinnon K, Varcoe C. Revisiting "who gets care?": Health equity as an arena for nursing action. ANS Adv Nurs Sci. 2009;32(2):118-27.

20. Hankivsky O, Cormier R. Intersectionality: Moving women's health research and policy forward [Internet]. Vancouver, BC: Women's Health Research Network; 2009. 1-68 p. Available from: www.whrn.ca

21.Thorne S. Ideas and action in a terrain of complexity. Nurs Philos. 2009;10(3):149-51.

22.Rehg E, Smithbattle L. On to the "rough ground": Introducing doctoral students to philosophical perspectives on knowledge. Nurs Philos. 2015;16(2):98-109.

23. Holmes D, Gagnon M. Power, discourse, and resistance: Poststructuralist influences in nursing. Nurs Philos. 2018;19(1):1-6.

24.Mackenzie I. Unravelling the knots: Post-structuralism and other "post-isms." J Polit Ideol [Internet].
2001;6(3):331-45. Available from: https://doi. org/10.1080/13569310120083035

25.Williams J. Understanding poststructuralism. Chesham: Acumen Publishing Limited; 2005. 1-180 p.

26.Dean M. Governmentality: Power and rule in modern society. London; Thousand Oaks, CA: Sage Publications; 1999.

27.Foucault M. The politics of truth. New York, NY: Semiotext; 2007.

28.Sochan AM. Stance and strategy: Post-structural perspective and post-colonial engagement to develop nursing knowledge. Nurs Philos. 2011;12(3):177-90.

29.Boucher LM, Marshall Z, Martin A, Larose-Hébert K, Flynn J V., Lalonde C, et al. Expanding conceptualizations of harm reduction: Results from a qualitative community-based participatory research study with people who inject drugs. Harm Reduct J. 2017;14(1):1-19.

30.United Nations Office on Drugs and Crime. Reducing the harm of drug use and dependence [Internet]. 2007. Available from: https://www.unodc.org/ddt-training/ treatment/ VOLUME D/Topic 4/1.VolD_Topic4_Harm_Reduction.pdf

31.Moore D. Governing street-based injecting drug users: A critique of heroin overdose prevention in Australia. Soc Sci Med. 2004;59(7):1547-57.

32.British Columbia Centre on Substance Use. Injectable opioid agonist treatment for opioid use disorder [Internet]. 2017. Available from: http://www.bccsu.ca/wp-content/ uploads/2017/10/BC-iOAT-Guidelines-10.2017.pdf

33.Paquette CE, Syvertsen JL, Pollini RA. Stigma at every turn: Health services experiences among people who inject drugs. Int J Drug Policy. 2018;57(104-110).

34.Weedon C. Feminist practice and poststructuralist theory. Cambridge, MA: Blackwell Publishers; 1997.

35.Coburn D. Health and health care: A political economy perspective. In: Bryant T, Raphael D, Rioux M, editors. Staying alive: Critical perspectives on health, illness, and health care. 2nd ed. Toronto, Ontario: Canadian Scholars' Press Inc.; 2010. p. 65-91.

36.British Columbia Minstry of Mental Health and Addictions. Escalating BC's response to the overdose emergency [Internet]. 2019. Available from: https://www2.gov.bc.ca/ assets/gov/overdose-awareness/mmha_escalating_bcs_ response_report_final_26feb.pdf

37.Rose N. Inventing our selves: Psychology, power, and 
personhood. New York, NY; Cambridge, United Kingdom: Cambridge University Press; 1996.

38.Rose N. Powers of freedom: Reframing political thought. New York, NY; Cambridge, United Kingdom: Cambridge University Press; 1999.

39. Moore D, Fraser S. Putting at risk what we know: Reflecting on the drug-using subject in harm reduction and its political implications. Soc Sci Med. 2006;62(12):3035-47.

40.Fraser S. 'It's your life!': Injecting drug users, individual responsibility and hepatitis $\mathrm{C}$ prevention. Health (Irvine Calif). 2004;8:199-221.

41.Petersen AR, Lupton D. The new public health: Health and self in the age of risk. London, UK: Sage Publications Ltd; 1996.

42.Rose N, Miller P. Political power beyond the State: Problematics of government. $\mathrm{Br} J$ Sociol. 2010;61(SUPPL. 1):271-303.

43. Miller PG. A critical review of the harm minimization ideology in Australia. Crit Public Health. 2001;11(2):176-8.

44.Foucault M. The birth of biopolitics: Lectures at the Collège de France 1978-1979. New York, NY: Palgrave Macmillan; 1979.

45.0'Malley P, Valverde M. Pleasure,freedom and drugs: The uses of "pleasure" in liberal governance of drug and alcohol consumption. Sociology. 2004;38(1):25-42.

46. Mugford S. Social change and the control of psychotropic drugs: Risk management, harm reduction and 'postmodernity.' Drug Alcohol Rev 12,. 1993;369-75.

47.Pollack S. Labelling clients "risky": Social work and the neoliberal welfare state. Br J Soc Work. 2010;40(4):1263-78.

48.Smith CBR. Harm reduction as anarchist practice: A user's guide to capitalism and addiction in North America. Crit Public Health. 2012;22(2):209-21.

49.Fischer B. The battle for a new Canadian drug law: A legal basis for harm reduction or a new rhetoric for prohibition? A chronology. In: Erickson P., Riley D., Cheung Y., editors. Harm reduction: A new direction for drug policies and programs. Toronto, ON: University of Toronto Press; 1997. p. 47-67.

50.Roe G. Harm reduction as paradigm: Is better than bad good enough? The origins of harm reduction. Crit Public Health. 2005;15(3):243-50.

51. Honan E. Writing a rhizome: An (im)plausible methodology. Int J Qual Stud Educ. 2007;20(5):531-46.
52.Fornssler B, McKenzie HA, Dell CA, Laliberte L, Hopkins C. "I got to know them in a new way": Rela(y/t)ing rhizomes and community-based knowledge (brokers') transformation of western and Indigenous knowledge. Cult Stud - Crit Methodol. 2014;14(2):179-93.

53. Holmes D, Gastaldo D. Rhizomatic thought in nursing: an alternative path for the development of the discipline. Nurs Philos. 2004;5(3):258-67.

54.Zibbell JE. Caught between the "soft" and "hard" arms of the state: A conceptual apparatus for situating the formative role of drug user organizations in national policy-making and local service delivery - A commentary. Subst Use Misuse. 2012;47(5):558-65.

55.Mcneil R, Kerr T, Pauly B, Wood E, Small W. Advancing patient-centered care for structurally vulnerable drugusing populations: A qualitative study of the perspectives of people who use drugs regarding the potential integration of harm reduction interventions into hospitals. Addiction. 2016;111(4):685-94.

56.McNeil R, Small W, Wood E, Kerr T. Hospitals as a "risk environment": An ethno-epidemiological study of voluntary and involuntary discharge from hospital against medical advice among people who inject drugs. Soc Sci Med [Internet]. 2014;105:59-66. Available from: http://dx.doi. org/10.1016/j.socscimed.2014.01.010

57. Meyer JB, Kaplan D, Charum J. Scientific nomadism and the new geopolitics of knowledge. Int Soc Sci J. 2001;53(168):309-21.

58.Buchanan J. Social work and drug use. Paylor I, Measham F, Asher H, editors. New York, New York: Open University Press; 2014.

59.Pauly B. Shifting moral values to enhance access to health care: Harm reduction as a context for ethical nursing practice. Int J Drug Policy. 2008;19(3):195-204.

To contact the author:

Trevor Goodyear, RN, MSN, MPH

University of British Columbia

School of Nursing

T201-2211 Westbrook Mall

Vancouver, BC, VT6 2B5

Canada

Email: trevor.goodyear@ubc.ca 